\title{
OBSERVACIONES SOBRE LA TIPOLOGIA DE LA LENGUA CHOROTEGA O MANGUE
}

\author{
Juan Santiago Quirós Rodríguez
}

\begin{abstract}
The purpose of this article is twofold. It presents a sketch of the main phonological and grammatical traits of Mangue (Chorotega).

It also argues that from the areal-typological viewpoint, the features of this language remmain typically those of what Kaufman has called the South Central group of Mesoamerican languages, in spite of Mangue's exodus from its original homeland in Chiapas, Mexico, and its subsequent 1000-year permanence in the borderland of Mesoamerica and the Intermediate Area.
\end{abstract}

\section{Introducción}

El chorotega o mangue, perteneciente a la familia de lenguas otomangues, se habló en las regiones limítrofes occidentales de Nicaragua y de Costa Rica, hasta mediados del siglo XIX.

De él conservo un vocabulario de 674 términos y una fraseología de 79 oraciones, recopilados en fechas diferentes por Rocha, Squier, Berendt, Brinton y Lehmann (Cfr. Bibliografía).

La naturaleza de dichos materiales -muy fragmentarios y recogidos por personas sin preparación especializada- no permite en lo absoluto ser exhaustivo (no se puede, por ejemplo, decir nada sobre los suprasegmentales ni sobre la oración compuesta). No obstante, su análisis detallado (Quirós, 1984) ha producido suficientes datos sobre la estructura de la lengua como para poder intentar situarla desde el punto de vista tipológico areal.

\section{Características fonéticas de la lengua mangue}

\subsection{Fonemas vocálicos}

Posiblemente, la lengua tuviera cuatro fonemas vocálicos, como parece haber sido la tónica de los idiomas otomangues:

anteriores

posteriores

\begin{tabular}{lll}
\hline altas & $/ \mathrm{i} /$ & $/ \mathrm{u} /$. \\
\hline bajas & $\mathrm{e} /$ & $/ \mathrm{a} /$ \\
\hline
\end{tabular}

Sin embargo, no existe total seguridad a este respecto (ibidem, pp. 58-72).

\subsection{Fonemas consonánticos}

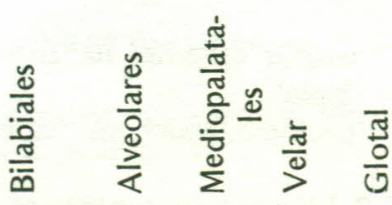

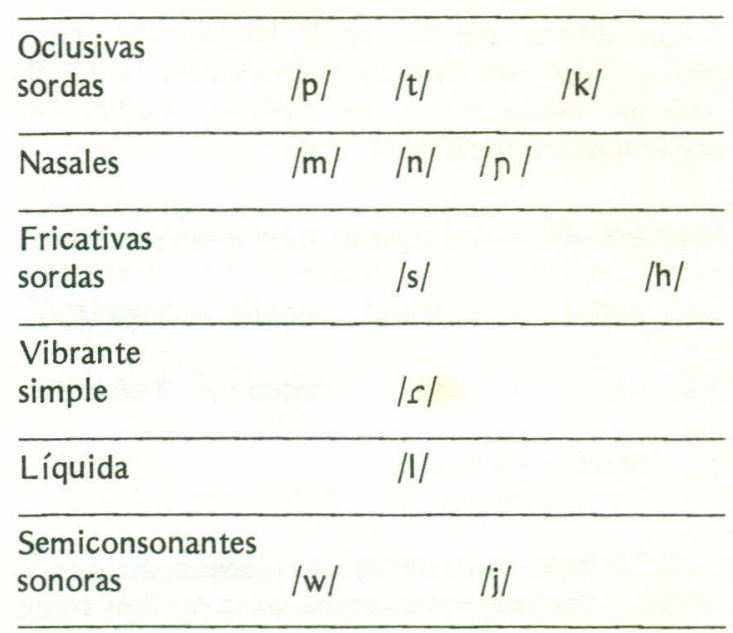

\subsubsection{Realizaciones de los fonemas consonánti-} $\cos$

Hay dos hechos que son los que Ilaman más la atención a este respecto. 
Por una parte, las oclusivas presentan realización sonora, facultativa aunque predominante, después de las nasales:
/p/ [p] pame
'bueno';
[b] ñumbui 'sol'
/t/ [t] teka 'uno';
[d] ndiro 'mano'
/k/ [k] nekupe 'cielo';
[g] ngura 'pie'

La condición facultativa de estas realizaciones se puede ejemplificar con el siguiente caso:

nampume $\sim$ nambume 'carne'

Por otra parte, tanto $/ \mathrm{t} /$ como $/ \mathrm{k} /$ presentan realizaciones africadas. La primera se realiza [ts] ante $[\mathrm{u}]$ y [o] (de haber una nasal precedente, esta realización era, probablemente, sonora y se representó ortográficamente $\operatorname{con} z)$. La segunda se realizaba facultativamente [ $\mathrm{t} \int$ ] (escrita $c h$ ) ante /i/.

\section{Ejemplos:}

/t/ tsujmu 'caliente', nanzogua 'corteza', ñunzu 'boca'

/k/ ngukimo, goochimo 'cabeza'

\subsubsection{Grupos consonánticos}

Los únicos que hay en la lengua, son $/ \mathrm{mp} /$, /nt/ y /nk/ que pueden manifestarse, tanto en posición inicial como en posición media. No hay grupos consonánticos finales:

$/ \mathrm{mp} / \mathrm{mb}$ ohue $=$ 'mi esposo' nimpe = 'sombrero'

/nt/ ndijpi = 'hombre' ninda = 'laguna'

/nk $\mid n k o^{i}=$ 'cuello' anco = 'hombre'

\section{Morfología flexiva}

Del estudio realizado sobre la lengua, queda claro que el chorotega presentaba tanto prefijos como sufijos; que recurría a la apofonía o alternancia vocálica para manifestar una categoría gramatical; que el sustantivo se flexionaba para número, posesión o ausencia de posesión y persona del poseedor; que el verbo lo hacía para persona, tiempo y modo; $y$ que el equivalente del adjetivo castellano era una subclase del verbo.
En los datos conservados no aparecen elementos derivativos de ningún tipo.

2.1 Flexiones exclusivamente verbales: los prefijos temporales y modales

La forma no flexionada del verbo puede usarse para traducir tanto el presente como el pretérito castellanos. Esto es, parece ser de igual naturaleza que la que Whorf (1971:133, nota 2) denominó "aseveración informativa" en la lengua hopi y que denota que se trata de un hecho real (no hipotético). Ejemplos:

koi gaimi ndiro 'ya él me dio la mano' koi yujwii 'ya anochece'

\subsection{1/e-/}

Este prefijo aparece en una forma verbal glosada como imperativo. Podría haberse tratado más bien de un indicador de presente, pues en chiapaneco (la lengua más cercana al chorotega), este tiempo se expresaba con el prefijo/i-/, que corresponde bien, fonéticamente, a la /e-/ del mangue:

ejeh 'itoma!'

\subsection{2. $/ \mathrm{u}-/$}

Indica imperativo (como en chiapaneco):

uji 'coge tú'

\subsection{3. $/ \mathrm{tu}-/$}

De acuerdo con las glosas, podría ser presente 0 pretérito. En chiapaneco /to-/ es prefijo de pretérito. Ejemplo:

tsupu nekajui 'voy al jardín'

zupunah 'parió' (cf. Quirós, p. 102-105).

\subsection{4. $/ \mathrm{ta}-/$}

Aparece en formas glosadas por futuros o imperativos castellanos. En chiapaneco un prefijo homófono indicaba futuro. Ejemplos:

tari 'beberás'

tapame 'sé bueno' 


\subsection{5. $/ \mathrm{m}-1$}

Posiblemente sea lo que Adam llama para el chiapaneco modo 'conjuntivo' (Adam., 1887:25); es decir, indica subordinación y simultaneidad.

\section{Ejemplo:}

mundamo 'cuando canta' (la glosa original es distinta, véase Quirós, ibidem, p. 107).

\subsection{6. $/ \mathrm{a}-1$}

Aparece en algunos verbos intransitivos (incluyendo equivalentes de adjetivos castellanos). En chiapaneco había un indicador de presente homófono. Ejemplo:

apame'(es) verde'

2.2. Flexiones exclusivamente nominales: prefijos de los nombres de posesión inalienable, pluralización apofónica.

2.2.1. Prefijos de los nombres de posesión inalienable

Los nombres de posesión inalienable presentan tres prefijos característicos.

\subsubsection{1. / $\mathrm{mp}-\mathrm{nt}-\mathrm{nk}-/$ 'un solo poseedor'}

Los alomorfos de este prefijo presentan indicios de condicionamiento fonológico. El primero y el último, que son los más frecuentes, se presentan respectivamente ante /a/ y ante /u/ e /i/. Hay, sin embargo, aparentes excepciones. Ejemplos:

$\begin{array}{ll}\text { mbasi } & \text { 'nalga' } \\ \text { ndiro } & \text { 'mano' } \\ \text { ngura } & \text { 'pie' } \\ \text { ngisa } & \text { 'barba' }\end{array}$

2.2.1.2 /kupa-/ 'varios poseedores' (chiapaneco copa-)

kupankoma'(nuestro) señor'

\subsubsection{3. $/ \mathrm{n}-/$ 'ningún poseedor'}

nohue 'hombre' (cf. mbohue 'marido')
2.2.2. Categoría expresada por afijación reemplazante

En chorotega existe, igual que en chiapaneco, la apofonía o alternancia vocálica para expresar el número de los sustantivos, fenómeno al que ya había aludido Berendt (Berendt, 1874 b: 3 y 9).

Con la vocal $-u-$, se indicaba el singular, y con $-i-$, el plural:

nyuri niri = 'flor, flores'

ngura ngira = 'pie, pies'

nasunyamo nasinyamo = 'muchacha, muchachas'

\subsection{Sufijos de persona}

En los casos observados no se dan secuencias de ellos, por lo tanto siempre aparece uno solo que, consecuentemente, siempre está en contacto directo con el tema.

\subsection{1. /-hu/ (aparece escrito como -jo o -ju).}

Indica primera persona del singular (sujeto o poseedor, en los casos observados):

koi pajo nama siñu 'ya voy a morir'

ngikojo 'mi pierna'

$$
\text { 2.3.2. /-ha-/ }
$$

Indica segunda persona (objeto en el único caso observado). En chiapaneco hay un sufijo idéntico (Albornoz, p. 27).

coy guaja 'ya te di'

\subsection{3. /-me/ (aparece escrito como - me o - mi)}

Pareciera estar asociado a la tercera persona, tanto complemento directo de verbo transitivo como sujeto de verbo intransitivo. Sin embargo, los materiales no permiten estar seguro sobre este caso de aparente ergatividad. Ejemplos:

koi yujmi 'ya anochece'

koi cupume 'ya lo vi' 


\subsection{Clases de palabras}

Con base en los afijos descubiertos y en su relación con los temas y raíces, se pueden distinguir tres clases mayoręs de dichos temas: verbos, sustantivos y partículas.

Los verbos poseen prefijos para tiempo, modo y aspecto. $Y$ sufijos para persona. Los equivalentes de los adjetivos españoles pertenecen, claramente, a esta categoría.

Los sustantivos poseen prefijos para forma poseída $y$ no poseída. Tienen sufijos para indicar persona del poseedor. Se flexionan, por medio de reemplazantes, para número.

Las partículas se caracterizan, sea cual sea su función, por carecer de flexiones. De las presentes en los datos, algunas equivalen a adverbios castellanos, como kopundpu 'cerca', haitsu 'lejos', yaji 'ayer'; otras a pronombres, como saho 'yo', neje 'él', semehmu 'nosotros'; otras, finalmente, a relatores, como se 'de' (nambroj se nati 'barro de olla'; misa se nirome 'gato de montaña'). Se dan también numerales, que de acuerdo con Lehmann constituían un sistema vigesimal (Lehmann 1920:856).

\section{Sintaxis}

En materia de sintaxis prácticamente lo único que se puede afirmar es que tanto el objeto como el sujeto se colocaban a la derecha del verbo (su orden relativo no se puede determinar, pues no se tiene ninguna oración en que ambos aparezcan), y que los equivalentes de los adjetivos castellanos se colocaban a la derecha de los sustantivos cuando funcionaban como modificadores directos del mismo (no como atributos), y que en las frases posesivas, el orden es poseído-poseedor.

Ejemplos:

koi gaimi ndiro = 'El ya me ha dado su mano' $\mathrm{V} \mathrm{O}$

En las intransitivas, el orden fue VS:

koi pindih Juana = 'La Juana está preñada'

koi pirami nimbui $=$ 'Ya viene la lluvia' V S

En la copulativa, el atributo antecede al sujeto:

$\begin{array}{lll}\underset{\mathrm{A}}{\text { pami nyumuta }} \mathrm{S} & =\text { 'La comida está buena' } \\ \underset{\text { nohue opome }}{\mathrm{S}}= & \text { 'un hombre alto' } \\ \text { misa se nirome } & = & \begin{array}{l}\text { 'gato montés' (lit. "gato } \\ \text { de montaña") }\end{array} \\ \text { nya ndiro } & = & \text { 'rama' (lit. "árbol brazo") }\end{array}$

\section{Comparación tipológica con las lenguas mesoa- mericanas}

\subsection{Rasgos fonéticos}

Por su origen, el chorotega pertenece a la que Kaufman ha llamado "zona sudcentral de Mesoamérica" (Kaufman, 1974:470) y, hasta donde lo permiten los datos, sigue manteniendo predominantemente las características de esa zona, como:
a. sistema vocálico de cuatro fonemas;
b. grupos de nasal más consonante oclusiva, que se realiza como oclusiva sonora prenasa-
lizada; c. presencia de las dos líquidas $/ \mathrm{l} / \mathrm{y} / \mathrm{r} /$;
ch. tenencia de $/ n /$.

Otros rasgos son, más bien, de carácter general mesoamericano, como:
a. la ausencia de oposición entre oclusicas sor- das y sonoras;
b. inclusión de solamente dos fricativas: /s/ y /h/ y;
c. de dos semiconsonantes $/ \mathrm{j} / \mathrm{y} / \mathrm{w} /$

\subsection{Rasgos léxicos y gramaticales}

En este campo, presenta los siguientes rasgos, muy extendidos en Mesoamérica (Campbell, 1979: 956-957):

a. economía lexicomorfológica, que se manifiesta en la producción de nuevos lexemas por medio de la combinación de un número limitado de morfemas, como en

$\begin{array}{lll}\text { 'lágrima' } & \text { nimbu nate } & \text { ("agua de los ojos") } \\ \text { 'rama' } & \text { ndiro nya } & \text { ("brazo de madera") }\end{array}$


b. numeración vigesimal;

c. orden poseído-poseedor;

ch. posesión inalienable de nombres de parentesco y de partes del cuerpo;

d. un afijo del tipo que Campbell llama "absolutivo nominal" (ibidem: 957) y al que hemos llamado de "ausencia del poseedor".

Además, presenta los dos siguientes, que son más particulares de la subárea y grupo genealógico de origen:

a. sujeto y objeto pospuestos al verbo, y

b. prefijación para indicar tiempo y modo.

\section{Conclusión}

Llama la atención cómo el chorotega, a pesar de tener en el momento de su extinción, por lo menos 1.000 años de permanencia en el área sur de Mesoamérica, (se cree que llegaron en el S. IX, Cfr. Quirós, 4-10), y, por lo tanto, estar en una posición limítrofe con el área intermedia, no adoptó, al parecer, rasgos de las lenguas de esta otra área que estaban cercanas, sino que mantuvo firmemente las características que le eran originales.

Se puede citar, a todo esto, que en las lenguas chibchas y misumalpas, no se dan grupos iniciales de nasal más consonante; se dan, con frecuencia, series opuestas de oclusivas sordas y sonoras; hay un mayor número de fricativas; el orden favorito es SOV; el poseedor precede a lo poseído y los afijos de tiempo y modo son, por lo común, sufijos.

\section{Bibliografía}

Adam, Lucien. La Langue Chiapaneque. Observa1887 tions grammaticales, vocabulaire méthodique, textes inédits, textes rétablis. Viena: Libraire de la Cour Impériale et Royale et de I'Université.

Albornoz, Fray Juan de. Arte de la lengua chiapa1875 neca. París: Ernest Léroun, éditeur.

Berendt, Karl Hermann. Diriá-Chiapaneco. Ma1874 a. nuscrito No. 143 de la Colección Lingüística de Berendt. Biblioteca "Brinton" de la Universidad de Filadelfia.
1874 b. Lengua chorotega o mangue y lengua maribia de Subtiaba. Manuscrito No. 144 de la Colección Lingüística de Berendt. Biblioteca "Brinton" de la Universidad de Filadelfia.

Brinton, Daniel G. Notes on the Mangue: an ex1886 tinct. Dialect formerly spoken in Nicaragua; read before the American Philosophical Society. Nov. 20, 1885. Philadelphia: American Philosophical Society, XXIII, 122 e 2E.

Campbell, Lyle and Mithun, Marianne. The Ian1979 guages of Native America: Historical and Comparative Assessment. Texas: University of Texas Press.

Holt, Dennis y Bright, William. "La lengua paya y 1976 las fronteras lingüísticas de Mesoamérica'.. En Las fronteras de Mesoamérica. 14a Mesa Redonda, Sociedad Mexicana de Antropología, 1: 149-56. México.

Kaufman, Terrence. "Areal linguistics and Middle 1974 American", en Current Trends in Linguistics, Vol. 10. La Haya: Mouton.

Lehmann, Walter. Zentral-Amerikas. Berlin: 1920 Ernst Vohsen.

Quirós R., Juan S. La lengua chorotega o mangue. inédita Análisis lingüístico de los materiales existentes. Tesis para optar al grado de Licenciado en Lingü ística. Facultad de Letras, Universidad de Costa Rica, 1984.

Rocha, Juan Eligio de la. Apuntamientos de la len1842 gua mangue. Manuscrito No. 140 de la Colección Lingü ística de Berendt. Biblioteca "Brinton" de la Universidad de Filadelfia.

Squier, E. G. Nicaragua; its people, scenery and 1860 monuments. Nueva York: Harper \& Brothers.

Whorf, Benjamín L. Lenguaje, pensamiento y rea1971 lidad. Barcelona: Seix Barral. 
